\title{
Effect of acetazolamide on blood gases and 2,3 DPG during ascent and acclimatization to high altitude
}

\author{
J.J. Milles, I.M. Chesner, S. Oldfield and A.R. Bradwell
}

Good Hope Hospital, Rectory Road, Sutton Coldfield, West Midlands, UK.

\begin{abstract}
Summary: Blood gases and red cell 2,3 DPG concentrations were measured during ascent and a stay for 6 days at $4846 \mathrm{~m}$ in 20 subjects. Acetazolamide improved $\mathrm{Pa}_{2} \mathrm{O}_{2}$ and reduced $\mathrm{pH}$ and $\mathrm{Pa}, \mathrm{CO}_{2} .2,3 \mathrm{DPG}$ concentrations were lower in the acetazolamide group during ascent and at high altitude. However, 2,3 DPG concentrations were significantly greater at high alititude in both the acetazolamide and placebo groups compared with low altitude. The acetazolamide group remained different from the placebo group during the stay at high altitude with higher $\mathrm{Pa}_{2} \mathrm{O}_{2}$, lower $\mathrm{PaCO}_{2}$, lower $\mathrm{pH}$ and lower $2,3 \mathrm{DPG}$ concentrations.
\end{abstract}

\section{Introduction}

Acetazolamide improves oxygenation during ascent to high altitude and reduces the severity of acute mountain sickness. ${ }^{1}$ Its effect on acclimatization to a high altitude is not known. This study aimed to monitor blood gases during ascent to high altitude and after a week's stay at $4846 \mathrm{~m}$. Frequent measurements of 2,3 diphosphoglycerate (2,3 DPG) were made. Rapid rises are known to occur in response to hypoxia but the changes during acclimatization and the effect of acetazolamide on 2,3 DPG are unknown.

\section{Methods}

Twenty normal subjects were studied during a walking ascent over 11 days to $4846 \mathrm{~m}$ and for the subsequent 6 days at that altitude. Subjects had been allocated randomly to placebo or acetazolamide $500 \mathrm{mg} /$ day. Blood gases and $\mathrm{pH}$ were measured on arterialized earlobe capillary samples in a Radiometer BGA Mk II analyser which had been standardized using an anaeroid barometer and specimen gases of known oxygen and carbon dioxide concentration, together with the standard $\mathrm{pH}$ buffers. Venous blood samples were taken for measurement of 2,3 DPG. Whole blood was mixed with trichloracetic acid to a final dilution of $6 \%$ and the supernatant separated and stored at ambient temperature. On return to Birmingham the samples were frozen at $-20^{\circ}$ until analysed using a Sigma kit method. Results were expressed as mmol per litre whole blood.

All results have been analysed using an unpaired Student $t$ test.

Correspondence: J.J. Milles M.A., M.R.C.P.

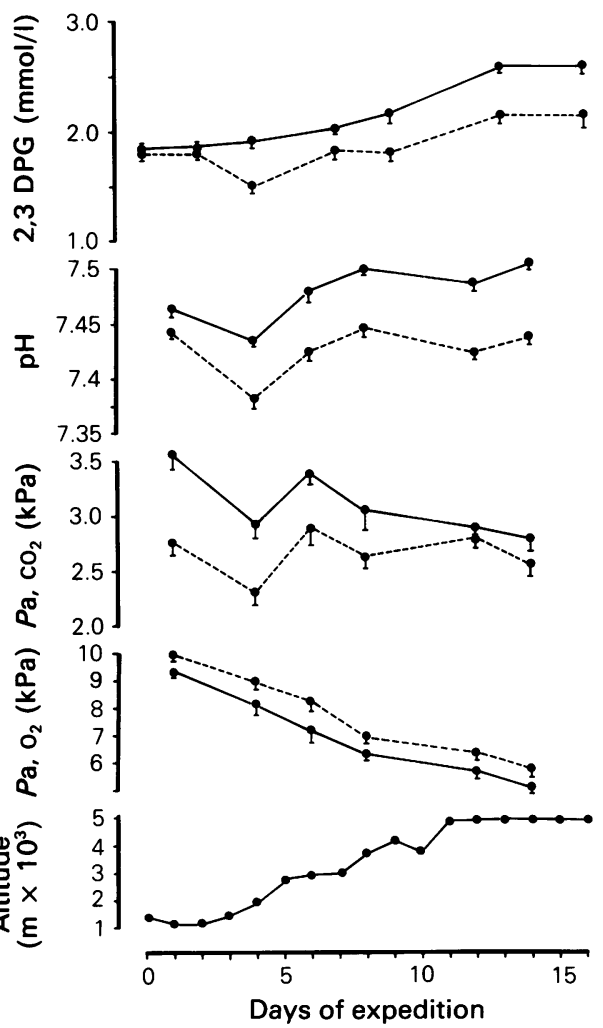

Figure 1 The changes in 2,3 DPG and blood gases on ascent and stay at high altitude in 20 normal subjects (mean \pm s.e.m.). Subjects on acetazolamide (---) or placebo (-).

(C) The Fellowship of Postgraduate Medicine, 1987 


\section{Results}

Mean $\mathrm{Pa}, \mathrm{O}_{2}$ fell progressively with altitude (Figure 1). $\mathrm{Pa}, \mathrm{O}_{2}$ was greater in the acetazolamide group $(P<0.001)$ at $1800 \mathrm{~m}$ and at all higher altitudes. This difference was maintained during the 6 days spent at $4846 \mathrm{~m} . \mathrm{Pa}, \mathrm{CO}_{2}$ levels were lower in the acetazolamide group at all times during ascent $(P<0.05)$, but there was no significant difference between the two groups at $4846 \mathrm{~m}$. Blood pH fell initially and then rose in both groups, the acetazolamide group having a consistently lower $\mathrm{pH}$ throughout $(P<0.01)$. There was an initial fall in 2,3 DPG concentration in the acetazolamide group but during ascent the level rose in both groups. However, 2,3 DPG concentration remained lower in the acetazolamide compared with the placebo group throughout ascent and during the 6 days at high altitude $(P<0.05)$. In both groups there was no change in 2,3 DPG concentration during the 6 days at high altitude.

\section{Discussion}

Our results show that the group taking acetazolamide had a higher $\mathrm{Pa}, \mathrm{O}_{2}$ than those taking placebo, both during ascent to high altitude and after 6 days at

\section{References}

1. Birmingham Medical Research Expeditionary Society. Mountain Sickness Study Group. Acetazolamide in the control of acute mountain sickness. Lancet 1981, i: 180 183.

2. Bradwell, A.R. \& Coote, J.H. The BMRES 1984 Medical Research Expedition to the Himalayas. Postgrad Med J 1987, 63: 165-167.

3. Forwand, S.A., Landowne, M., Follansbee, J.N. \& Hansen, J.E. Effect of acetazolamide on acute mountain sickness. $N$ Engl J Med 1968, 279: 839-845.

4. Hlastala, M.P. Interactions between $\mathrm{O}_{2}$ and $\mathrm{CO}_{2}$. In:
$4846 \mathrm{~m}$. This suggests that the beneficial effects of acetazolamide are maintained during acclimatization. Acetazolamide causes a metabolic acidosis and stimulates ventilation, resulting in a lower $\mathrm{pH}$ and $\mathrm{Pa}, \mathrm{CO}_{2}$ as confirmed in this study and by others. ${ }^{3,4}$

We have shown that 2,3 DPG concentrations rise rapidly on ascent to altitude and that this rise is maintained during 6 days at high altitude in both groups. Acetazolamide reduces the rise in 2,3 DPG and this difference between the groups is also maintained during the stay at high altitude. An early adaptive mechanism to hypoxia is a reduced affinity of haemoglobin for oxygen due to a rapid rise in 2,3 DPG. ${ }^{5}$ This makes more oxygen available to the tissues. However, this shift to the right of the oxygen dissociation curve is counterblanced by the rise in $\mathrm{pH}$ resulting in a net Bohr shift to the left.

The rise in whole blood 2,3 DPG may in part be accounted for by an increase in red cell mass. However, our previous work has shown that no significant rise in packed cell volume would occur during the time period covered by this expedition. ${ }^{6}$

The group taking acetazolamide had a lower $\mathrm{pH}$ and lower 2,3 DPG levels than control subjects. The net effect of these changes on the oxygen dissociation curve and its modification by acetazolamide requires further study.

Sutton, J.R., Jones, N.L., Houston, C.S. (eds) Hypoxia Man at Altitude. Thieme - Stratton Inc, New York, 1982, pp. 17-23.

5. Lenfant, C., Torrance, J., English, E. et al. Effect of altitude on oxygen binding by haemoglobin and on organic phosphate levels. J. Clin Invest 1968, 47: 26522656.

6. Howell, A. \& Cove, D.H. Birmingham Medical Research Expeditionary Society 1977 Expedition. The diuresis and related changes during a trek to high altitude. Postgrad Med J 1979, 55: 471-474. 